\title{
Self Health Assessments as per Family/Household Health Survey 2017: Exploring new avenues to improve health and health reporting in Saudi Arabia
}

Asharaf Abdul Salam ( $\square$ asalam@ksu.edu.sa )

King Saud University Center for Population Studies

\section{Research}

Keywords: Age groups, administrative areas, chronic diseases, injuries, health systems

Posted Date: June 18th, 2021

DOI: https://doi.org/10.21203/rs.3.rs-609072/v1

License: () (i) This work is licensed under a Creative Commons Attribution 4.0 International License. Read Full License 


\section{Abstract}

Background: Public health data for dissemination and discussion in Saudi Arabia are limited but the new initiatives of General Authority of Statistics creates many national surveys. One of the most recent one, the Family/Household Health Survey - 2017 aims to fill the gaps in health information data on many population and health indicators. This research aims at appraising the self-assessed health and to examine age-sex and geographic differentials and the probable interconnections with chronic diseases, injuries and periodic examinations.

Data and Methods: The National Family/Household Health Survey conducted in October-December, 2017 covered both Saudi and non-Saudi households from 13 administrative areas through a random sample procedure involving primary sampling units and secondary sampling units. A portion of the published data on self-assessment of health, chronic diseases, injuries, and periodic medical examinations were analyzed.

Results: More than half of the persons in the Kingdom, reportedly, are in good health; more so among females than males: their proportions decreased with age up to 40 years and thereafter increased sharply. However, the major regions have lesser proportion of good health people than the others. On the contrary, the prevalence of chronic diseases increases with age, in both general and Saudi population, but with variations across specific diseases - hypertension, diabetes, cancer, and cardiovascular diseases: there are pertinent geographic differentials. On the other hand, there are injuries (from traffic accidents and others) occurred at house, work/school, public place, and other places; pertinent with geographic variations. Moreover, age, sex, and regional differences in periodic health examinations have a contributing effect on health assessments. Moreover, the median age shows a pattern resembling adults assessing good health; chronic diseases after 50s; injuries before 40s; periodic medical examinations in 50s; with females at a lower age, both in general and Saudi population.

Discussions and Conclusions: The national health system played an important role not only in health status and health assessments but also in building confidence and trust and thereby enhancing optimism, realism, recognition, selfawareness, and acceptance of physical condition. Thus, age, sex, and regional variations in health assessment are born out of chronic diseases, injuries, and periodic medical examinations and also of expectations and experiences. Generation of such information, effective dissemination, and regular discussions at various levels followed by in-depth analyses raise health and health care.

\section{Background}

Self-assessment is a process that includes self-observation, self-judgment, and self-evaluative reaction resulting in performance measurement (1). Thus, a person's self-assessments reflect actual health condition resultant of diseases and other physical conditions including injuries. So, it is the sum total of all health experiences adjusted by expectations. Thus, self-assessment of health reflects the objective health status, health needs, and health infrastructure requirements at a macro level. Moreover, analyses of such assessments and comparisons facilitates identification of at risk (vulnerable) people requiring more attention and care: this leads to inputs about health specialities, major disease interventions, lateral programs, and services planning (2).

Arab country endeavors on health care facilitate creation of necessary services by considering the least disadvantaged population living in rural and remote areas; tackling the absence of qualified staff and operational equipments; health of girls and women; preventive health and early diagnosis; sensitization of care; etc. $(3,4)$. Combined with these commitments are the economic and social progress facilitating life expectancy and maternal, infant and child mortality, which in turn influences the health scenario, and thereby, health assessments. Still, vital services including medical/nursing care clinics, health centers, geriatric departments, and preventive measures such as awareness

Page 2/20 
campaigns, and accessible and acceptable services are in demand to deal with the vulnerable groups such as children below 5 years, women of reproductive age, and elderly $(2,3,4)$.

Studies of health perceptions and assessments help the health professionals and managers to raise an alarm to improve affordable care by attending to special needs of at risk people (5). On the other hand, they facilitate to capture pathological changes and associated symptoms beforehand and beyond the disease diagnosis, which aids control actions in case of chronic diseases and thereby health improvement $(6,7)$. Moreover, perceived, self-assessed health reveals the positivism developed through education and facilitated by marital relationships, nature of work, social support, financial preparedness, access to healthcare services, social and economic advantages, and employment (8).

\section{Research Problem And Objectives}

Saudi Arabia occupies four-fifths of the Arabian Peninsula in terms of land area and population; and thus plays a major role in initiating population policies, programs, and monitoring and evaluation in order to improve health and human development $(3,9)$. Population in Saudi Arabia, in general, have positive views towards life, death, and overall health along with hopefulness of family life, and deeper awareness of Allah/God, combined with religious practices (10). However, the demand for vital services including medical and nursing care, clinics, health centers, and geriatric departments are addressed to improve health of poor and marginalized population through adoption of legislations, and necessary control and continued monitoring (4). Moreover, systems of health management to combat with the increasing life style diseases like hypertension, diabetes, cancers, and cardiovascular diseases prerequisite surveys, analyses, and researches $(10,11,12)$.

Al-Yousuf et al. explained the principal health issues in the country like communicable diseases, including malaria and schistosomiasis, and motor vehicle accidents taking a major toll of public health system due to the emergence of life style diseases and injuries in the era of increasing life expectancy, changing morbidity patterns, decreasing mortality, and improving quality of life (2). Several studies conducted to light into the perceived health status of elderly in Saudi Arabia explain economic difficulties, limited access to health services, lack of resources, pressures of setting up uniform curriculum, economic growth, modernization, globalization, increasing affluent life styles, and diversity of pilgrims (9, $11,13,14,15,16,17,18,19)$.

In the light of the change in information requirements, the General Authority of Statistics, Saudi Arabia builds statistical information through surveys on demography, housing, labor force, household expenses, umrah, elderly, disability, and family/household health. A part of the published data of the family/household health survey analyzed further to explain the pertinent aspects of self-assessed health and its inter linkages with chronic diseases, injuries, and periodic medical examinations.

\section{Data And Methods}

The Family/household Survey 2017 was carried out to generate a reliable dataset for the health planners and decision makers and to serve as a reference to improve, update and monitor implementation of health policies and strategies, to make international and regional comparisons, to evaluate implementation processes, and to identify needy population (20). This survey followed the General Authority of Statistics (GASTAT) general population and housing census framework 1431H (2010) to cover Saudi and non-Saudi households. The Kingdom, for the purpose of the survey, was divided into non-overlapping homogeneous parts - as independent society (Primary Sampling Units - PSU): from where the households (secondary sampling units - SSU), were drawn following a regular random sampling procedure, as shown in Table 1. 
Table 1

Sample design and sample size

\begin{tabular}{|lll|}
\hline Administrative area & Sampling units & $\begin{array}{l}\text { Sampling units } \\
\text { (households) }\end{array}$ \\
\hline Riyadh & 207 & 2,726 \\
Makkah Al-Mokarramah & 242 & 4,256 \\
Al-Madina Al-Monawarah & 92 & 1,656 \\
Al-Qaseem & 66 & 1,188 \\
Eastern Region & 168 & 2,024 \\
Aseer & 90 & 1,620 \\
Tabouk & 73 & 1,314 \\
Hail & 65 & 1,170 \\
Northern Borders & 70 & 1,260 \\
Jazan & 71 & 1,278 \\
Najran & 64 & 1,152 \\
Al-Baha & 60 & 1,080 \\
Al-Jouf & 66 & 1,188 \\
Total & 1,334 & 24,012 \\
\hline
\end{tabular}

This survey gathered details of household members, insurance, smoking, health status, accidents and injuries, healthy lifestyle patterns, marriage and household planning, and fertility and child mortality through a structured format. A pilot survey was conducted, prior to the actual survey, during 8th October-1 November, 2017 by means of investigators and supervisors trained through introductory lectures, techniques of personal interviews, dealing with households, monitoring and auditing data collection. The actual survey took place between 10th November and 3rd December, 2017.

The classified data analyzed as follows,

- Percentage of the total population for each sex, age group, and administrative area

- Prevalence rate of chronic diseases by sex, age group, and administrative area using the formula $P R=\frac{\mathrm{Pat}}{\mathrm{P} t i} \times 100$; where $\mathrm{Pai}$ is the persons suffering from a disease at age $\mathrm{i}$ and $\mathrm{Pti}$ is the total population at age $\mathrm{i}$

- Percentage of injured to the total population for age and administrative area by using the formula $P I=\frac{\mathrm{P} i i}{\mathrm{Pti}} \times 100 ;$ where $\mathrm{Pii}$ is the persons injured $\mathrm{i}$ and $\mathrm{Pti}$ is the total population at age $\mathrm{i}$

- Percent of injured by place to the total injured for age and administrative area

- Percentage of persons undergoing periodic medical examinations to the total population by age group, and sex for general and Saudi population 
- Median age of male, female, total population for general and Saudi population for self-assessed health, chronic diseases, periodic examinations, type of injuries and place of injury by applying the formula

Median $=\operatorname{lm} d+\left(\frac{\frac{\mathrm{n}}{2}-\sum \mathrm{fx}}{\mathrm{fmd}}\right) \times \mathrm{i}$; where Imd is the lower limit of the median class; $\mathrm{n}$ the sample size; $\sum \mathrm{fx}$ is the cumulative frequency above the median class; $f_{m d}$ is the frequency of the median class; $i$ is the class interval

\section{Results}

Results of the analyses are classified into self-assessed health and factors influencing self-assessed health covering non-communicable chronic diseases and injuries and age factor. All these sections are explained across age, administrative area and periodic examinations for both general and Saudi population, wherever possible.

\section{a. Levels of self-assessed health}

The self-assessed (perceived) health status as good, as reported in the survey 2017, demonstrates that females are at an advantage: more than two-thirds reporting good health (Fig. 1). These results show the supremacy of females over males on their health status, which might have reasons of reduced risks and exposures to road traffic accidents, pollution, occupational hazards, infections from crowded commercial places, food poisons from restaurants, long travels, frequent visits to deserts, and so on.

Moreover, there is marked age differentials in the percentage of population assessing health as good (Fig. 2). A higher proportion of both males and females in ages 15-19 years and 20-24 years assesses their health as good. But thereafter, with increasing age, their percentages fall up to age 40-44 years: further increased in proportions till old age. This trend is similar to both males and females, but with a steep increase in females of age 40-44 to 50-54 years and thereafter a stagnation till 60-64 years. This male female difference indicates advantages of females of 40 to 54 years (the older adulthood, typically mothers of grown up children): probably, attributed to the reduced domestic responsibilities, higher self-esteem, and increased parental responsibilities. This transition in a woman's life might impact positively upon health assessment.

On the other hand, males show a marked increase in their percentage reporting good self-assessed health (an increase of 20.8 points) between the age group of $60-64$ and $65+$ years. That is, males in older ages have better self-assessed health than younger males. This is a unique situation, contrary to the expected compression of morbidity theory in the old age. Probably, old aged males in Saudi Arabia are more realistic and optimistic than others in accepting ill-health and senility (21).

However, the male female gap in health assessment as good is negligible in the early ages (15-19 and 20-24 years); thereafter it increases slowly till 40-44 years and widens further till 50-54 years (gap is nearly 40 points). In the further age groups, the difference reduces and converges in the old age (13.3 points difference). Such a male female gap in the self-assessed health is clearer across major age groups: minimum ( 2.0 points $-80.2 \%$ of females as against $78.3 \%$ of males) in younger ages (15-19 and 20-24 years); higher (23.2 points - 64.1\% of females as against $40.9 \%$ of males) in the middle ages (25-59 years) and moderate ( 22.1 points $-83.6 \%$ in females as against $61.5 \%$ in males) in old age (60 years and above). Overall, 79.2 percent of young adults, 49.7 percent of middle aged and 69.8 percent of old aged have good self-assessed health. It is also to be noted that the percentage of persons assessing good health is low in the age groups from $30-34$ years to $45-49$ years: 45.8 percent ( $37.2 \%$ of males, $60.1 \%$ of females) and with a male female gap of 22.9 points. 
Males of age $40-44$ years reported the lowest (32.1\%) and $65+$ years the highest $(72.9 \%)$ as against females of age $40-44$ years $(54.3 \%)$ and $65+$ years $(86.2 \%)$. As of the total persons, the lowest percentage in $40-44$ years $(40.1 \%)$ and highest in 65 + years (78.4\%). In all cases the lowest proportions are found in the age of early 40 s and highest in the old age. This might be introspective for the poor health perceptions and assessment at peak adult ages and good at senile ages (13). On the other hand, it explains the connections with the myth/reality of age 40 as the starting point of noncommunicable diseases like hypertension, diabetes, cardiovascular diseases, kidney troubles, liver complications, etc. Thus, the early 40 s are troublesome suffering ages while the old age is an age of acceptance.

Saudi Arabia is divided into 13 administrative areas: major areas (Riyadh, Makkah, Madina, and Eastern region) and others $(21,22,23.24)$. Major areas have a low percentage of persons reporting good self assessed health; among them Makkah Al-Mokarramah has the lowest (48.7\%) while Eastern Region has the highest (56.9\%). The highest male female difference is in Eastern Region (25.3 points), followed by Riyadh (20.3 points), Al-Madina Al-Monawarah (19.3 points) and Makkah Al-Mokaramah (16.0), in the order. Of the other areas Al-Baha has the highest percent reporting good selfassessed health (74.3\%), followed by Jazan (73.5\%), Tabouk (73.4\%), Aseer (73.2\%), Northern Borders (73.2\%), and Hail (70.1\%), in the order.

Al-Qaseem, Al-Baha and Al-Jouf have higher male female gap (more than 22 points). In short, major areas have 51.7 percent of persons reporting good self-assessed health as against 70.8 percent in other areas, with a male-female gap of 19.5 points and 21.1 points, correspondingly. So, based on the percentage of persons with good self-assessed health, administrative areas could be classified into three namely, prominently good health having more than 70 percent (Aseer, Tabouk, Hail, Northern Borders, Jazan, and Al-Baha), moderately good health having 60-70 percent (Al-Qaseem, Najran, and Al-Jouf) and subtly good health having below 60 percent (Riyadh, Makkah Al-Mokarramah, Al-Madina AlMonawarah, and Eastern Region). On the other hand, the administrative areas are classified into three on the basis of male female difference in good self-assessed health such as: minimum gap - less than 20 percentage points (Jazan, Makkah Al-Mokarramah, and Al-Madina Al-Monawarah); moderate - 20-23 points (Riyadh, Aseer, Tabouk, Hail, Northern Borders, Najran, Al-Baha); and high - 24 points and more (Al-Qaseem, Eastern Region, and Al-Jouf).

\section{b. Factors influencing self-assessed health}

Self-assessment of health might reflect objective health condition resulting form diseases, disabilities, and periodic medical examinations/medications. These three variables are analyzed and interpreted here for their probable influence on health status and assessments.

\section{i. Chronic Non-communicable Diseases}

Differences and patterns of health assessments could be, possibly, attributed to the prevalence rate of noncommunicable chronic diseases and injuries. Four major diseases, recorded, are hypertension (High BP), diabetes, cancer, and cardiovascular diseases (CVD); the common chronic diseases in the Kingdom. These diseases together have a prevalence rate of 182.3 per 1000 persons, which is considered to be higher (Table 2). 
Table 2

Prevalence rate of chronic diseases (age 15 years and above) per 1000 persons

\begin{tabular}{|c|c|c|c|c|c|c|c|c|c|c|}
\hline \multirow{2}{*}{$\begin{array}{l}\text { Age } \\
\text { groups/areas }\end{array}$} & \multicolumn{5}{|c|}{ General population } & \multicolumn{5}{|c|}{ Saudi Population } \\
\hline & BP & Diabetes & Cancer & CVD & Total & BP & Diabetes & Cancer & CVD & Total \\
\hline $15-19$ & 0.8 & 4.7 & 0.3 & 1.3 & 7.1 & 1.1 & 5.4 & 0.3 & 1.3 & 8.1 \\
\hline $20-24$ & 2.2 & 6.4 & 0.5 & 1.7 & 10.7 & 2.2 & 7.3 & 0.6 & 1.9 & 11.9 \\
\hline $25-29$ & 3.0 & 8.4 & 0.9 & 0.9 & 13.2 & 4.1 & 9.9 & 1.1 & 0.7 & 15.8 \\
\hline $30-34$ & 10.3 & 14.1 & 0.8 & 1.0 & 26.2 & 10.7 & 17.7 & 1.4 & 1.1 & 31.0 \\
\hline $35-39$ & 22.4 & 29.2 & 0.8 & 3.1 & 55.6 & 28.8 & 32.2 & 1.3 & 3.9 & 66.2 \\
\hline $40-44$ & 47.5 & 61.8 & 1.7 & 5.7 & 116.8 & 63.2 & 65.1 & 4.1 & 9.3 & 141.8 \\
\hline $45-49$ & 100.7 & 111.3 & 1.6 & 9.9 & 223.6 & 121.8 & 129.2 & 1.8 & 14.4 & 267.2 \\
\hline $50-54$ & 192.0 & 233.5 & 3.8 & 20.7 & 450.0 & 234.4 & 259.3 & 4.4 & 28.5 & 526.6 \\
\hline $55-59$ & 282.3 & 343.6 & 3.8 & 35.3 & 665.0 & 302.7 & 344.7 & 5.0 & 42.3 & 694.7 \\
\hline $60-64$ & 434.1 & 485.3 & 10.2 & 69.6 & 999.2 & 406.2 & 441.1 & 10.8 & 61.2 & 919.3 \\
\hline $65+$ & 916.5 & 901.4 & 15.1 & 201.1 & 2034.0 & 522.0 & 521.7 & 7.2 & 119.3 & 1170.3 \\
\hline Total & 78.1 & 90.2 & 1.8 & 12.1 & 182.3 & 93.4 & 102.0 & 2.4 & 15.9 & 213.7 \\
\hline Riyadh & 67.9 & 83.0 & 2.1 & 10.4 & 163.4 & 87.4 & 101.6 & 2.9 & 14.8 & 206.7 \\
\hline Makkah Al- & 87.6 & 103.3 & 2.0 & 14.7 & 207.6 & 100.4 & 108.1 & 2.5 & 19.4 & 230.4 \\
\hline 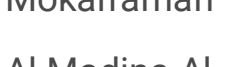 & 67.1 & 86.5 & 0.7 & 6.1 & 160.5 & 72.9 & 96.0 & 1.1 & 8.0 & 178.0 \\
\hline Monawarah & 81.6 & 85.0 & 0.5 & 9.7 & 176.7 & 102.8 & 104.7 & 0.7 & 12.8 & 221.0 \\
\hline Al-Qaseem & 77.0 & 83.5 & 1.9 & 10.2 & 172.5 & 96.2 & 99.4 & 2.6 & 14.8 & 213.0 \\
\hline Eastern & 93.5 & 98.3 & 1.8 & 14.1 & 207.6 & 106.5 & 107.5 & 2.3 & 17.3 & 233.6 \\
\hline Region & 84.8 & 104.8 & 0.9 & 18.2 & 208.6 & 89.7 & 108.4 & 1.1 & 15.4 & 214.6 \\
\hline & 73.1 & 87.7 & 2.0 & 13.2 & 176.0 & 94.9 & 106.7 & 2.7 & 15.6 & 219.8 \\
\hline & 85.3 & 84.1 & 2.1 & 8.8 & 180.3 & 103.4 & 99.0 & 2.8 & 11.6 & 216.8 \\
\hline rall & 81.6 & 74.9 & 2.4 & 15.6 & 174.5 & 90.9 & 80.1 & 3.0 & 18.1 & 192.1 \\
\hline $\begin{array}{l}\text { Northern } \\
\text { Borders }\end{array}$ & 59.5 & 80.7 & 1.3 & 12.2 & 153.7 & 69.4 & 97.7 & 2.8 & 16.4 & 186.3 \\
\hline Jazan & 86.6 & 98.0 & 2.3 & 17.1 & 204.0 & 92.6 & 106.8 & 2.8 & 19.8 & 222.0 \\
\hline Najran & 60.2 & 80.1 & 1.6 & 12.8 & 154.8 & 74.3 & 96.6 & 2.3 & 18.0 & 191.2 \\
\hline Al-Baha & 78.1 & 90.2 & 1.8 & 12.1 & 182.3 & 93.4 & 102.0 & 2.4 & 15.9 & 213.7 \\
\hline Al-Jouf & & & & & & & & & & \\
\hline Total & & & & & & & & & & \\
\hline
\end{tabular}

Out of these diseases, diabetes is the most common recording a prevalence rate of 90.2 , followed by hypertension (78.1) cardiovascular diseases (12.1) and cancer (1.8). There is a positive relation between prevalence and age: increasing prevalence along with age. These diseases are higher among those aged 40 years and above; conforming to 
an already established fact of 40 years as the beginning of health complications and life style diseases. It increases thereafter, seriously, adding vulnerability to old age, moreover, evidencing multiplicity of diseases (co-morbidity), especially in old age (65 + years). In short, an older person aged 65 years and above has more than two diseases (prevalence rate of 2034 per 1000 persons). In comparison, Saudi population has slightly higher prevalence rates up to age 60 years, in all the four chronic diseases considered, but with variations across age. In other words, disease prevalence in old aged Saudi population (60-64 and 65 + years) remains lower in comparison with the total population of the same age. That is, the prevalence rate of diseases of Saudi population differ from that of the total population, while analyzed through age groups, especially in old age.The picture is clearer while analyzing across the broad age groups: all these diseases have its presence since adolescent/youth, but their prevalence increases with age: old age (60 years and above) marks an age of all these diseases exemplifying the theory of compression of morbidity (Fig. 3). Both the general population as well as the Saudi population follow a similar trend but with varying rates of prevalence across age groups. Saudi population has a comparatively lower prevalence rate in old age, which could be attributed to their life styles, food habits, occupations, and living arrangements. But during other ages Saudi population has comparatively higher prevalence of these diseases as compared to general population.

Tabouk, Aseer and Makkah Al-Mokarramah areas have high prevalence rate, almost equal among the general population. While Al-Baha has a prevalence close to those mentioned areas, others have low prevalence. Najran has the lowest prevalence, followed by Al-Jouf, Al-Madina Al-Monawarah, and Riyadh in the order. In the case of Saudi population, Aseer has the highest prevalence of chronic diseases, followed by Makkah Al-Mokarramah, Al-Baha, AlQaseem, and Hail, in the order. Al-Riyadh has a prevalence of 206.7, referring that nearly 207 persons (out of 1000) suffer from one or more of the diseases considered including co-morbidity. On the other hand, Al-Madina Al-Monawarah has the lowest prevalence, followed by Najran, Al-Jouf, and Jazan in the order. Overall, such variations of disease prevalence in some of the major areas and minor areas make the area wise differences negligible.

\section{ii. Injuries}

Another probable cause of ill-health inflicting upon self-assessments would be the injuries of various kinds victimized by the population, sources of which are grouped into traffic accidents and others (Table 3). No doubt, roads and traffics forms a major source of injury not only in the Arabian Gulf but also in the developing countries, due to unsafe road conditions, driving regulations, and security measures. It shows that 2.2 percent of persons, in general, victimize injuries: its percentage among Saudi is slightly lower (1.3\%). Of the total injured, the share of traffic accidents is less than one-third, in both the groups. There are certain age groups vulnerable to injuries; both traffic accidents and others. Old age has seriously affected, as expected, due to reduced motor skills and physical capabilities. 
Table 3

Percent of Population injured ( 15 years and above) by type injury

\begin{tabular}{|c|c|c|c|c|c|c|}
\hline \multirow[t]{2}{*}{ Age groups/regions } & \multicolumn{3}{|c|}{ General population } & \multicolumn{3}{|c|}{ Saudi Population } \\
\hline & $\begin{array}{l}\text { Traffic } \\
\text { accidents }\end{array}$ & Others & Total & $\begin{array}{l}\text { Traffic } \\
\text { accidents }\end{array}$ & Others & Total \\
\hline $15-19$ & 0.6 & 1.0 & 1.6 & 0.5 & 0.7 & 1.2 \\
\hline $20-24$ & 1.0 & 1.0 & 2.0 & 1.0 & 0.9 & 1.8 \\
\hline $25-29$ & 0.8 & 1.2 & 2.0 & 0.5 & 0.8 & 1.3 \\
\hline $30-34$ & 0.8 & 1.5 & 2.3 & 0.6 & 0.7 & 1.4 \\
\hline $35-39$ & 0.6 & 1.4 & 2.1 & 0.5 & 0.6 & 1.1 \\
\hline $40-44$ & 0.7 & 1.5 & 2.2 & 0.2 & 0.6 & 0.8 \\
\hline $45-49$ & 0.6 & 1.8 & 2.4 & 0.2 & 0.7 & 0.9 \\
\hline $50-54$ & 0.6 & 1.9 & 2.6 & 0.3 & 0.8 & 1.1 \\
\hline $55-59$ & 0.4 & 1.2 & 1.6 & 0.2 & 0.6 & 0.8 \\
\hline $60+$ & 0.8 & 3.1 & 3.9 & 0.6 & 2.6 & 3.2 \\
\hline Total & 0.7 & 1.5 & 2.2 & 0.5 & 0.8 & 1.3 \\
\hline Riyadh & 0.5 & 1.0 & 1.4 & 0.4 & 0.5 & 0.8 \\
\hline Makkah Al-Mokarramah & 0.6 & 1.9 & 2.5 & 0.3 & 0.8 & 1.1 \\
\hline Al-Madina Al-Monawarah & 0.5 & 0.6 & 1.1 & 0.3 & 0.4 & 0.7 \\
\hline Al-Qaseem & 0.4 & 1.2 & 1.6 & 0.3 & 0.8 & 1.1 \\
\hline Eastern Region & 1.0 & 1.4 & 2.3 & 0.6 & 0.8 & 1.5 \\
\hline Aseer & 1.1 & 1.5 & 2.6 & 0.9 & 1.1 & 2.0 \\
\hline Tabouk & 2.4 & 5.3 & 7.7 & 1.4 & 3.0 & 4.4 \\
\hline Hail & 0.7 & 1.8 & 2.5 & 0.6 & 0.7 & 1.2 \\
\hline Northern Borders & 0.3 & 3.9 & 4.2 & 0.3 & 2.3 & 2.6 \\
\hline Jazan & 0.9 & 0.7 & 1.5 & 0.8 & 0.5 & 1.3 \\
\hline Najran & 1.5 & 3.0 & 4.5 & 1.2 & 2.0 & 3.2 \\
\hline Al-Baha & 0.6 & 0.9 & 1.5 & 0.4 & 0.8 & 1.2 \\
\hline Al-Jouf & 0.5 & 0.5 & 1.0 & 0.4 & 0.3 & 0.7 \\
\hline Total & 0.7 & 1.5 & 2.2 & 0.5 & 0.8 & 1.3 \\
\hline
\end{tabular}

Risks of injuries increases with increasing age (from adolescent/youth to old aged): those in working (adult) age have lesser risks, both in general and Saudi population. There is an increase in the incidences of injuries (other than traffic accidents) to the old aged population, which could, probably, have a direct impact on their perceived (self-assessed) health (Fig. 4). On the other hand, the major administrative areas have lesser risks of injuries as compared to other smaller areas. This, probably, shows the safety standards, regulations, and quality of housings, pavements, and infrastructure. 
A large majority of these injuries took place in the house: risks of movements, complexity of equipments, modern bathrooms or even the interpersonal conflicts possible (Fig. 5). There are many injuries from the workplace/schools, and also from public places, pointing to, occupational hazards, school based injuries, and accidents/falls at public places.

While those injured at house are highest in the old age, followed by 45-49 years and 50-54 years respectively, but are less frequent among adolescent/youth ages. Three age groups (40-44, 45-49, and 50-54) are more susceptible to injuries in the workplace/school (Fig. 6). Injuries at public places are higher for age groups 25-29, 30-34, and 35-39 years but lower in 45-49,50-54, and $65+$ years. Injuries from other places are more frequent in case of those aged 55-59 years but lowest in case of 40-44 years. These differences indicates the age susceptibility of injuries by place.

Area wise, injuries from home are more frequent in Northern Borders, Al-Qaseem, and Makkah Al-Mokarramah but least frequent in Al-Madina Al-Monawarah, Hail, and Al-Jouf. On the other hand, injuries from workplace/school are more in Northern Borders, Hail, Al-Jouf, and Makkah Al-Mokarramah whereas lesser in Al-Madina Al-Monawarah, Jazan, and AlBaha. Injuries at public places are higher in Al-Baha, Hail, and Al-Qaseem whereas less in Jazan, Al-Jouf, and Tabouk.

iii. Periodic medical examinations

A recent health care mechanism introduced to monitor public health is the periodicity of examinations as a part of disease surveillance based on a strategy of symptom identification, diagnosis, and treatment at the right time to control further infections or deteriorations leading to disabilities. Nearly one-third of the persons, without respect to age, undergo periodic medical examinations ranging from weekly to more than a year among both the general and Saudi population. In comparison, females undergo periodic examinations more often than males (Table 4).

Table 4

Percentage of persons undergoing periodic medical examinations

\begin{tabular}{|lllllll|}
\hline \multirow{2}{*}{ Frequency } & \multicolumn{3}{c}{ General population } & \multicolumn{3}{c|}{ Saudi Population } \\
\cline { 2 - 7 } & Male & Female & Persons & Male & Female & Persons \\
\hline Weekly & 0.5 & 0.5 & 0.5 & 0.6 & 0.6 & 0.6 \\
Monthly & 2.7 & 4.4 & 3.4 & 3.3 & 4.8 & 4.1 \\
Quarterly & 4.8 & 6.2 & 5.3 & 5.3 & 6.4 & 5.9 \\
Half yearly & 6.7 & 7.1 & 6.9 & 6.2 & 6.9 & 6.6 \\
Yearly & 11.2 & 10.4 & 10.9 & 6.7 & 8.3 & 7.5 \\
More than an year & 6.4 & 7.4 & 6.8 & 5.8 & 6.6 & 6.2 \\
Total & 32.2 & 36.1 & 33.7 & 28.0 & 33.7 & 30.7 \\
\hline
\end{tabular}

\section{c. Age Factor}

Health status and assessments have close link with age and developmental stages, mostly, related to physical capabilities and physiological functioning. Thus, it is essential to consider interrelationship while addressing the selfassessed health. It is, therefore, assumed that people of young age - adults - often consider themselves as healthier due to their peak physical performance involving motor skills and bodily functions. The persons reporting good selfassessed health are at a young adult age (32.7 years): both males and females (Table 5).

On the other hand, median age, as an indicator, shows the pattern of chronic disease prevalence in the specific population groups. For e.g. 56.1 years is median age of general population with chronic diseases: Saudi population 
have a slightly higher median age (59.1 years). Age differences along specific diseases are in such a way that cancers have the earliest age of onset (in general population and Saudi population) starting immediately on completing 50 years; for general (61.5 years) and Saudi population (63.1 years); diabetes and hypertension have a different age (before cardiovascular but after cancers), in both general and Saudi population.

Table 5. Median age calculated for various dimensions of health status (15 years and above)

a. Assessments and factors

\begin{tabular}{|l|r|r|}
\hline Indicators & Total population & Saudi Population \\
\hline Population assess own health as good Male & 32.9 & - \\
Female & 32.6 & - \\
Total & 32.7 & - \\
\hline Chronic diseases & & \\
High BP & 57.3 & 59.4 \\
Diabetes & 55.3 & 58.5 \\
Cancer & 52.2 & 519 \\
Cardiovascular diseases & 61.5 & 63.1 \\
Total & 56.9 & 59.1 \\
\hline Type of injury & & \\
Traffic accidents & 34.2 & 31.1 \\
Other than traffic accidents & 39.1 & 37.1 \\
Total & 37.5 & 34.3 \\
\hline Place of injury & & - \\
In the house & 41.3 & - \\
At work/School & 38.9 & - \\
Public place & 34.6 & - \\
Others & 36.1 & \\
\hline
\end{tabular}

b. Medical examinations

\begin{tabular}{|l|r|r|r|r|r|r|}
\hline \multirow{2}{*}{ Frequency } & \multicolumn{3}{|c|}{ Total population } & \multicolumn{3}{c|}{ Saudi Population } \\
\cline { 2 - 7 } & Male & Female & Persons & Male & Female & Persons \\
\hline Weekly & 52.2 & 61.0 & 54.5 & 56.0 & 60.3 & 58.6 \\
Monthly & 54.1 & 48.9 & 52.0 & 57.3 & 51.8 & 54.3 \\
Quarterly & 50.7 & 48.8 & 49.9 & 51.9 & 51.0 & 51.4 \\
Half yearly & 44.7 & 41.1 & 43.5 & 46.0 & 42.5 & 44.4 \\
Yearly & 40.6 & 36.9 & 39.4 & 40.5 & 37.8 & 39.0 \\
More than an year & 40.6 & 37.0 & 39.2 & 38.6 & 36.9 & 37.6 \\
\hline
\end{tabular}

Injuries happens to the general population at an earlier age, the peak adulthood age (in the 30s): earlier to Saudi population. Traffic accidents which occurs earlier to others in both general and Saudi population. However, injuries at public places happen earlier than at house or work/school. Adding up to this are the age details of periodic medical examinations, the frequency of which increases along median age of the person.

\section{Discussions}

Arab countries in general and Saudi Arabia in particular have strengthened their health systems and health delivery networks to address various sectors of population offering a mix of services from both public and private facilities, complemented by insurance schemes. Still, there is an urge for improving coverage of poor and marginalized population for pollution control, reducing exposures, continued monitoring, combating spread of harmful practices, women's health, and geriatrics $(4,10,21,23)$. Moreover, health services accessible to the least disadvantaged rural population, tackling the absence of qualified staff and operational equipment, dealing with social and economic status 
of girls and women, investing in preventive health through early diagnosis, sensitization and care, etc., have an impact on health and human development in the Arab countries $(3,13)$.

However, the public sector facilities cater to nearly 80 percent of beneficiaries $(20,22)$ have made significant improvements in maternal and child health $(25,26)$. Still, there are concerns about economic difficulties and limited access to health services in the Kingdom, especially in the case of old aged persons $(11,27)$. Still, the changes over the years in the Saudi health system in response to the demands, especially of the vulnerable (children, women, and elderly) have been appreciated. It has been revamped with curative services and trained personnel connected with a network of hospitals, dispensaries, health offices, maternal and child care centers, health posts, etc., which are proved to be successful especially when integrated with literacy levels, women's socio-economic status, qualifications of health staff, general behavior, and interactions between patients and medical personnel $(2,3,15)$. As a result, morbidity and premature mortality declined in Arab countries in general and Saudi Arabia in specific: mostly those related to child birth, communicable diseases, nutrition, new born, and maternal disorders (12). This contrasts with the situation of few Arab countries having a large percentage of population, especially of rural areas, deprived of access to health facilities resulting in high levels of maternal and infant mortality (3).

Such an impressive commitment and health networking might have an impact on health status and health care of population, which play a role in health assessments; nearly three-fifths report a good health. These show not only the faith in the system consisting of qualified staff, operational equipments, efficient catering of at risk people, early diagnosis, and sensitization but also with practices and religiosity integrated to the life style $(3,10,16)$. However, the huge male female difference in the proportion assessing health as good (68.9\% versus $48.5 \%)$ is unexpected. But this could be explained for the basis of biological superiority of female, differential life expectancy, exposure levels to adverse environmental conditions (pollution, smoke, sand storms, heat, cold, etc.), road traffic and occupational hazards, and so on $(9,16,17)$. On the other hand, women's shortcomings such as impact of marital dissolutions, dependence on activities of daily living, and psychopathology were stressed in the Saudi Arabian context $(11,25)$. At the same time, the gendered health system prevalent in the Kingdom assigns women with lower standards of education, nutrition, or work opportunities considering themselves repository of males, thus, limiting their access to politics, physical mobility, and reproductive capacity (17). A joint effect would be the realization, recognition, and acceptance of health condition. Thus, giving rise to an elevated self-assessment.

In short, women are protected and safeguarded in the society within the four walls of the family by men, community, society, and religion. Possibly, this protection offers them good health and disease free life, in turn, making them positive, optimistic and hopeful increasing their visit to health facilities and diagnostics, and thus the perceived health (16). Probably, the situation of women in the Kingdom has improved to provide structures for fulfilling their lives and financial means, increased education and employment, delay in marriages, fertility reductions, reduced emphasis on women's role on motherhood, and improved resources and opportunities $(19,28)$.

A similar observation from the data that a higher percentage of old aged are in good health. Moreover, their positive views, influenced by socio-medical factors, towards the end of life and attitude towards death, overall good health, hopefulness of family, as well as deeper awareness of Allah are well rooted in the Saudi Arabian culture $(10,16,21,23)$. This could probably light into the argument that despite the emergence of lifestyle diseases and injuries, rapid socioeconomic development in recent decades has had a visible impact on the health status, especially of life expectancy, changing morbidity pattern, decreasing mortality rates, and thus improving quality of life $(2,15)$. Moreover, fundamental changes in the health services such as strengthening primary health care as basic health service for all members of the community at the first level of contact with health services (18) would also have contributed to improvement of elderly health and thus, their assessments. 
The notion of compression of morbidity at the later years of life has been evidenced here, especially at age 60 years and above, reporting multiple pathologies of chronic nature - hypertension, diabetes, cancer, and cardiovascular diseases (29). While the general population suffers at the rate of 182.3 persons per 1000 , those aged $60-64$ years suffer at the rate of 999.2 and that of 65 years and above at 2034.0. These inflated prevalence are expected with the rapidly increasing life expectancy with the changing morbidity and mortality scenario. While comparing age sex differentials in health assessment and chronic diseases, it is really inspiring to explore the reasons. Probably, health consciousness, periodic monitoring, care of at risk, and specialized attention of health sector might explain this paradox. Identification of elderly and women as vulnerable attract them to intensive caring mechanisms and at the same time increases consciousness leading to reporting to health facilities for monitoring, thus, perceiving health positively $(1,2,10,17,20,29)$. Thus, these data refers to the consciousness and acceptance of the health condition, especially by the females and the elderly, reveal the crucial role of active lifestyle and habitual sport participation that determines health perception, in addition to financial preparedness, access to health services as well as social advantages and activities $(5,6,8,30)$.

Even the injuries, although, 2.2 percent in general and 1.3 percent in Saudi population, their incidences increases with increasing age; exemplifying the physical incapacities associated with age, both in case of those due to traffic accidents and others with least differences between general and Saudi population. There are wide regional variations in the injuries, which might be attributed to the living environment differentials.

The major administrative areas such as Riyadh, Makkah Al-Mokarramah, Al-Madina Al-Monawarah, and Eastern Region differ from the rest in all these aspects - health assessment, chronic diseases, and injuries. These urbanized and modernized regions have pressures of not only population but also occupation, local administration, housing, personal expenditures, road traffic, family, education, and healthcare: all those impacting upon chronic diseases and injuries, and thus, health assessments, Other administrative areas differ, to an extent, on those dimensions: Al-Baha, Aseer, and Tabouk reports higher levels of self-assessments; Najran reports lowest prevalence of chronic diseases; and Al-Jouf reports lowest percent of injuries. Possibly resulted from health assessments' dependence on literacy, social and economic status, qualification of health staff, general behavior, and patient-medical personnel interactions (3). On the contrary, availability and accessibility of good sanitation and clean water in the cities of major areas coupled with wellestablished health care facilities improve their expectations, recognitions, consciousness, periodic examinations, intake of necessary medications, and constant self-monitoring (levels of blood pressure, glucose, cholesterol, and uric acid and functioning of heart, kidney, lungs and liver). This prompt, the educated urban population to assess their health very objectively $(2,9,10,14,15,16,17,18)$.

People of early adulthood ages are found to assess their health as good more frequently than others (adolescents/youth or old aged). But the median age of those reportedly suffering from chronic diseases are above 50 years, both general population and Saudi population. Early adult age (below 40 years) is susceptible to injuries. Moreover, those undergoing periodic medical examinations are also lower than 40 years; both general and Saudi population. These information explain the age specific risks of chronic diseases and injuries, and thus the need for constant monitoring through the established three tier health care system across the sectors $(\mathrm{MoH}$, other government entities, and private) of the Kingdom (2).

The survey report published by the General Authority of Statistics, in their website, does not offer much scope for cross classifications or explorations uniformly for age, sex, and administrative area comparing between general and Saudi population. The table for health assessment offers data by age and administrative area; chronic diseases and injuries by age and administrative area for general and Saudi population (but not sex wise); periodic examinations by age, sex, and administrative area. These limit the scope of further analysis and explorations, comparisons, and interpretations in a uniform manner. It is also important to the academic community to access the raw data so as to statistically analyze 
to create empirical comparisons and evaluations for the benefit of quality health care services, which in turn enhances health status and also popularize health reporting in the Kingdom.

\section{Conclusions}

Health sector in Saudi Arabia has undergone improvements in administration, management, programs, budgets, and targets, and thereby health system development, coverage and performance. Hence, health seeking behavior and thus health status of the population has enhanced significantly, in the recent years. Population as a whole, reportedly, has a good self-assessed health; whose differentials are observed across age groups and geographic areas. More females, older aged and small (minor) administrative area residents have good self-assessed health, which points to subjective evaluations dependent upon expectations, optimisms, realism, and acceptance shaped by the culture, tradition, and religiosity.

Three factors attributed, with the available data namely, chronic diseases, injuries and periodic medical examinations in the context of emerging health system development-health status interrelationship; but the socio-economic transformations in the Kingdom give importance to recognition, acceptance, realism, and optimism emerges as more important.

Thus, it is important to initiate continued efforts to creation, dissemination, and discussion of primary survey data. Such efforts shall pave way for introspection, which in turn empower and enrich the public health status in Saudi Arabia.

\section{Declarations}

\section{Ethics approval and consent to participate}

This section is not applicable, as this research is based on data published by the General Authority of Statistics, Saudi Arabia.

\section{Consent for publication}

This section is not applicable as this research is based on data published by the General Authority of Statistics, Saudi Arabia. However, author expresses his consent to publish.

\section{Availability of data and material}

As this research utilized publicly available data published the General Authority of Statistics, Saudi Arabia, there are no restrictions

\section{Competing interests}

Authors declare that there are no competing interests or conflicts

\section{Funding}

Deanship of Scientific Research at King Saud University, Riyadh, for its funding of this research through the Research Group No. RGP-329

\section{Authors' contributions}


AAS - Initiation, concept development, data compilation, analysis, writing

\section{Acknowledgements}

The authors would like to extend their sincere appreciation to the Deanship of Scientific Research at King Saud University, Riyadh, for its funding of this research through the Research Group No. RGP-329. Other than the authors, this research group includes Prof. Rshood M. Al-Khraif, Dr. Ibrahim Elsegaey, Dr. Abdullah Al-Mutairi and Ms. Faten AlMutairi as team members. The authors thank the Deanship of Scientific Research and RSSU at King Saud University for their technical support.

\section{References}

1. Bose S, Oliveras E, Edson WE. 2001. How can Self-assessment improve the quality of healthcare? Operations Research Issue Paper 2(4) Published for the U.S. Agency for International Development (USAID) by the Quality Assurance (QA) Project. Bethesda, MD and JHPIEGO Corporation, Baltimore, MD.

2. Al-Yousuf M, Akerele TM, Al-Mazrou YY. Organization of the Saudi health system. Eastern Mediterranean Health Journal 2002; 8 (4/5): 645-653.

3. Boutayeb A, and Serghini M. Health indicators and human development in the Arab region. International Journal of Health Geographics 2006; 5(12): 61-74.

4. United Nations. 2002. The Arab Plan of Action on Ageing to the Year 2012. Beirut. Economic and Social Commission for Western Asia.

5. Medeiros SM, Silva LSR, Carneiro JA, et al. Factors associated with negative self-rated health among noninstitutionalized elderly in Montes Claros, Brazil. Ciencia \& Saude Coletiva 2016; 21 (11): 3377-3386.

6. Stenholm S, Kivimaki M, Jytha M, et al. Trajectories of self-rated health in the last 15 years of life by cause of death. Geriatric Epidemiology 2016; 31 (2): 177-185.

7. Jeres-Roig J, Souza DLB, Andrade FLJP, et al. Self perceived health in institutionalized elderly. Ciencia \& Saude Coletiva 2016; 21 (11): 3367-3375.

8. Khan HTA, Flynn, M. Self-reported health status of older adults in Malaysia and Singapore: Evidence from the 2007 Global Ageing Survey. Applied Research Quality Life 2016; 11 (3): 687-705.

9. Memish ZA, Venkatesh S, Ahmed QA. Travel epidemiology: the Saudi perspective. International Journal of Antimicrobial Agents 2003; 21 (2): 96-101.

10. Karlin NJ, Weil J, Felmban W. Aging in Saudi Arabia: An exploratory study of contemporary older persons' views about daily life, health, and the experience of aging. Gerontology and Geriatric Medicine 2016; 2 (1): 1-9.

11. Al-Shammari SA, Mazrou YA, Jarallah JS, et al. Appraisal of critical, psychosocial, and environmental health of elderly in Saudi Arabia: a household survey. The international Journal of Aging and human Development 2000; 50 (1): 43-60.

12. Mokdad AH, Jaber S, Aziz MIA, et al. The state of health in the Arab world, 1990-2010: an analysis of the burden of diseases, injuries, and risk factors. Lancet 2014; 383 (9914): 309-320. 
13. Salam AA, Elsegaey I, Khraif RM, et al. Components and Public Health Impact of Population Growth in the Arab World. PLoS ONE. 2015; 10 (5): e0124944.

14. Alkabba FA, Hussein GA, Kasule $\mathrm{OH}$, et al. Teaching and evaluation of medical ethics in Saudi public medical colleges: cross-sectional questionnaire study. BMC Medical Education 2013; 13:122 https://doi.org/10.1186/14726920-13-122.

15. Aldossary A, While A, Barriball L. Health care and nursing in Saudi Arabia. International Nursing Review $2008 ; 55$ (1): 125-128.

16. Jarallah JS, Al-Shammari, SA. Factors associated with health perception of Saudi Arabia. Journal of Cross Cultural Gerontology 1999; 14 (4): 323-334.

17. Aldosari, H. The effect of Gender norms on women's health in Saudi Arabia. Policy Paper No. 1. Washington The Arab Gulf States Institute 2017.

18. Al-Mazrou YY. Primary health care in Saudi Arabia: its development and future prospective. Journal of Family and Community Medicine 2002; 9 (2) 15-16.

19. Al-Gabbani M. Aging population in Saudi Arabia. IGC Tunis 2008 Aug. 15.

20. General Authority of Statistics. Elderly Survey. Riyadh. Government of Saudi Arabia. 2017.

21. Al-Khraif RM, Al-Mutairi AN, Alradihan KO, et al. Levels and Determinants of Retiree Life Satisfaction in Saudi Arabia Journal of Population Ageing 2019; 12 (1): 109-126.

22. Salam AA, Elsegaey I, Khraif R, et al., Population distribution and household conditions in Saudi Arabia: reflections from the 2010 Census. SpringerPlus 2014; 3 (1): 530.

23. Al-Khraif RM, Al-Mutairi AN, Alradihan KO, et al. Retiree home ownership in Saudi Arabia: the role of geographic, demographic, social and economic variables Journal of Population Research 2018; 35 (2): 169-18.

24. Khraif R, Salam AA, Potty RS, et al. Variations in basic demographics consequential to population size of governorate in Saudi Arabia SpringerPlus 2016; 5(1):1431.

25. Khraif R, Salam AA, Al-Mutairi A, et al. Fertility Behaviour of Working Women in Saudi Arabia: A special case of King Saud University, Riyadh. Human Fertility 2018; http://doi.org/10.1080/14647273.2018.1449971.

26. Alrouh H, Ismail A, Cheema S. Demographic and health indicators in Gulf Cooperation Council nations with an emphasis on Qatar. Journal of Local and Global health Perspectives 2013:3 http://dx.doi.org/10.5339/jlghp.2013.3

27. Khraif R, Salam AA, Elsegey I, et al. Changing Age Structures and Ageing Scenario of the Arab World. Social Indicators Research 2015; 121 (3): 763-785

28. Rashad H. Demographic Transition in Arab countries: a new perspective. Journal of Population Research 2000; 17 (1): 83-101.

29. Beltran-Sanches H, Jimenez MP, Subramanian SV. Assessing morbidity compression in two cohorts from the health and retirement study Journal of Epidemiology and community health 2016; 70 (10): 1011-1016. 
30. Condello G, Capranica L, Stager J, et al. Physical activity and health perception in aging: do body mass and satisfaction matter? A three path mediated link. PLoS ONE 2016; 11 (9): 1-16.

\section{Figures}

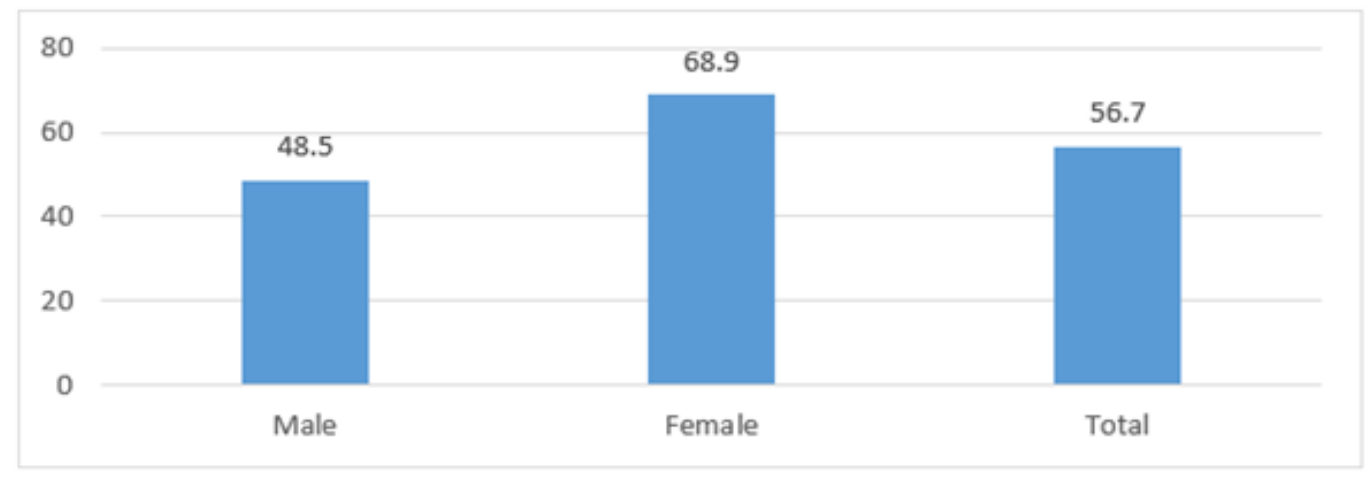

\section{Figure 1}

Percentage of males and females ( 15 years and above) who self-assessed their health as good

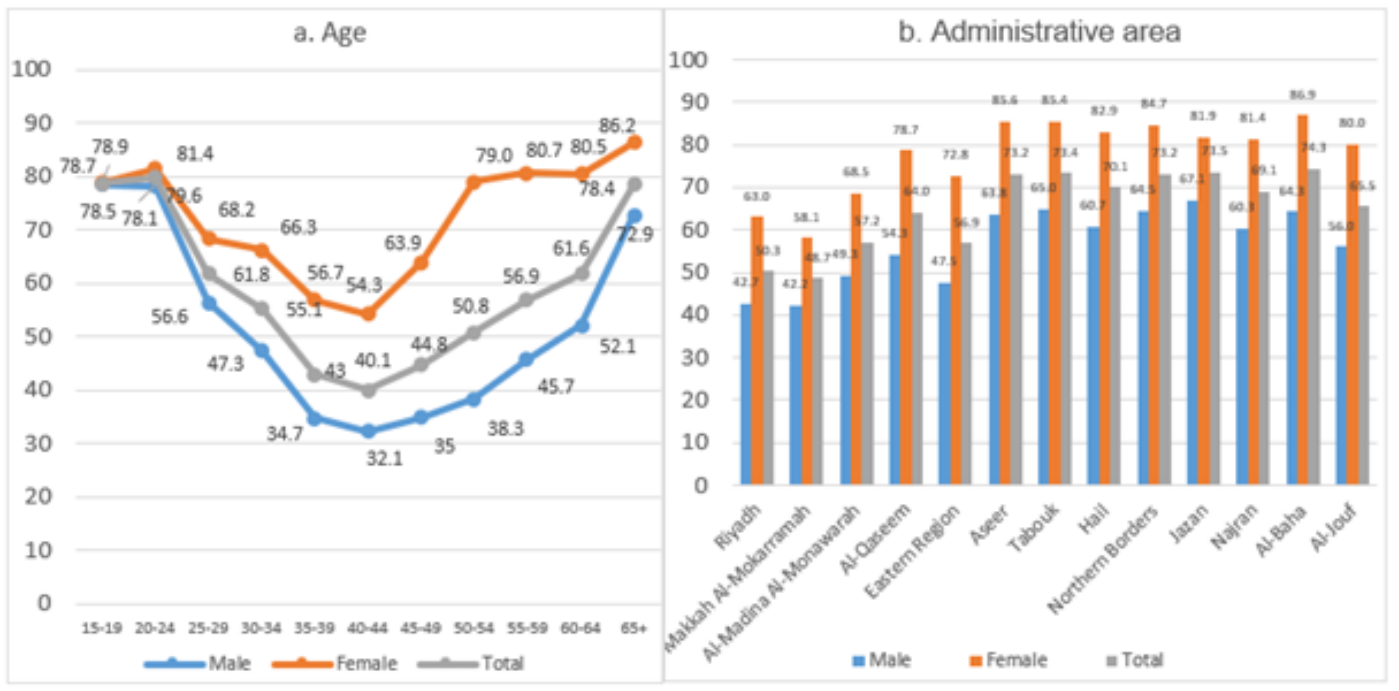

Figure 2

Assessment of health as good (15 years and above) by a. age and b. administrative area 
a. Broad age groups

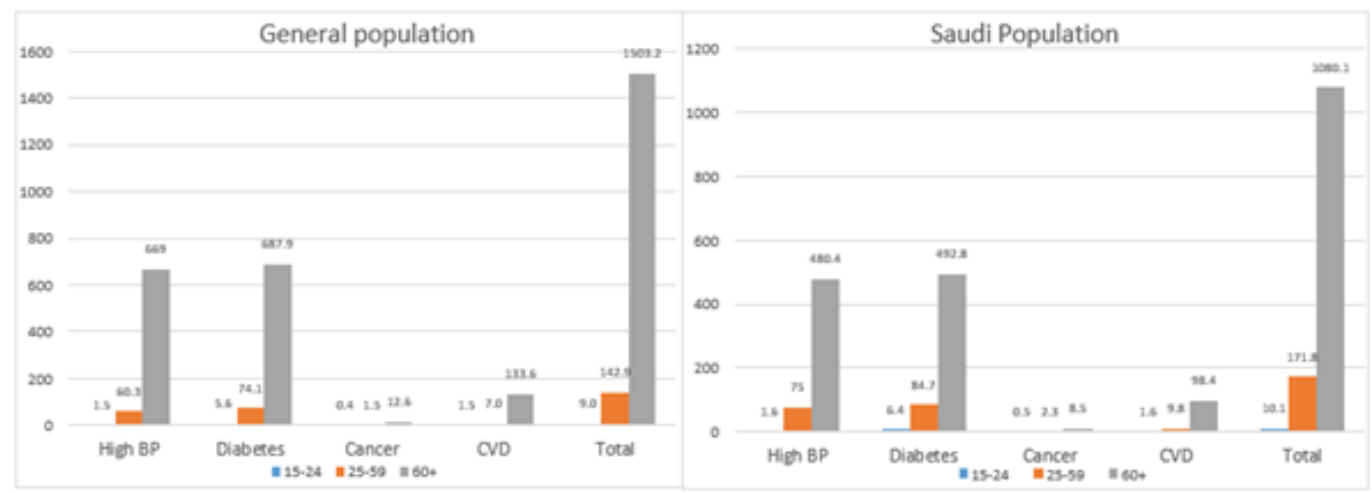

b. Administrative areas classified

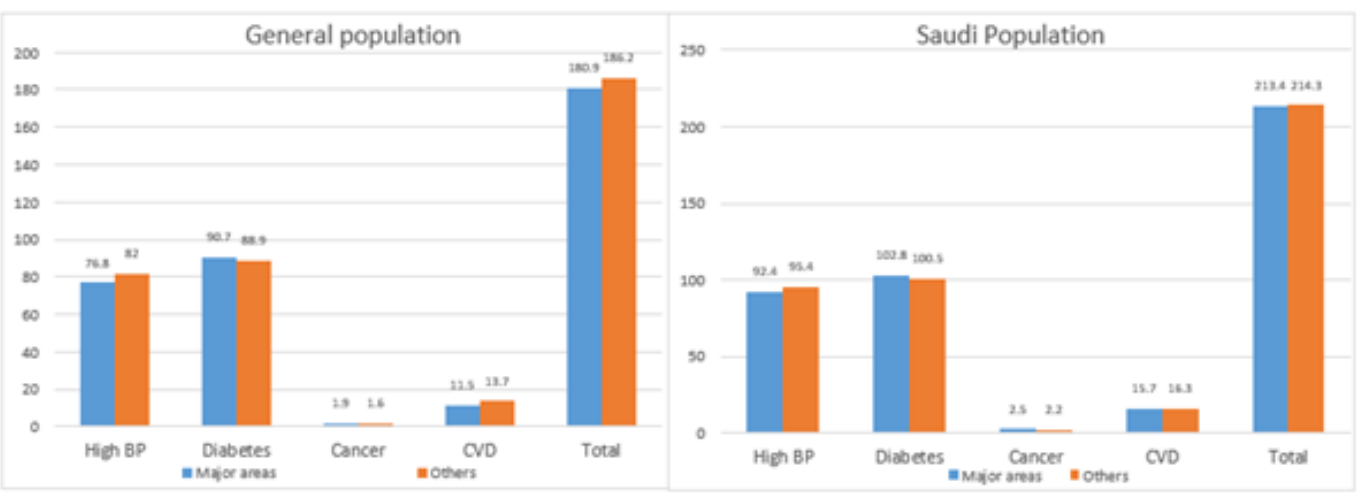

\section{Figure 3}

Prevalence of chronic diseases by a. broad age groups and b. administrative areas classified 


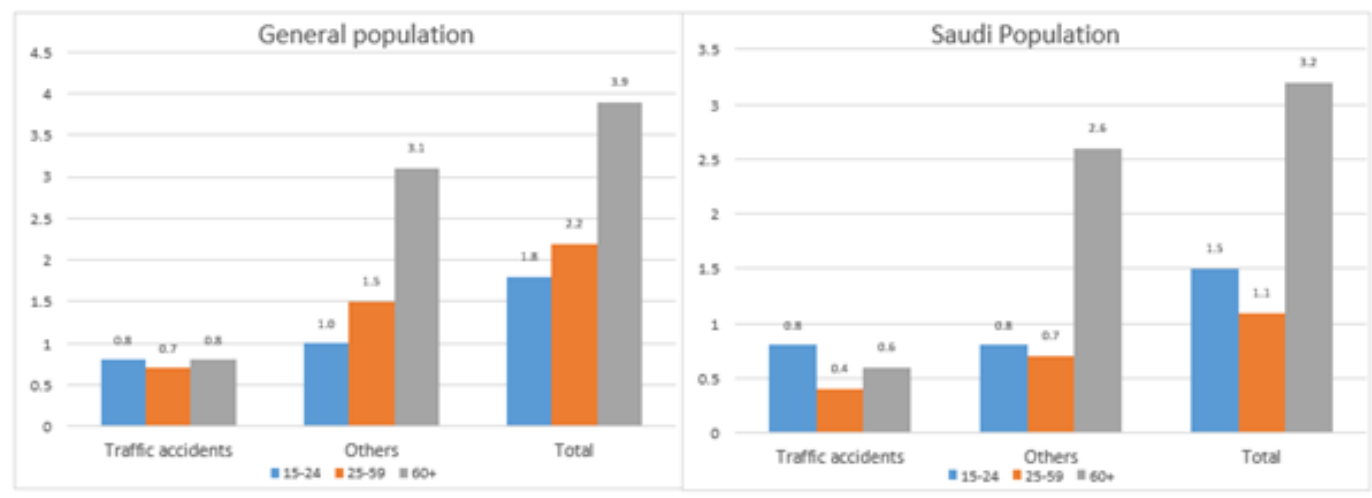

b. Administrative areas classified

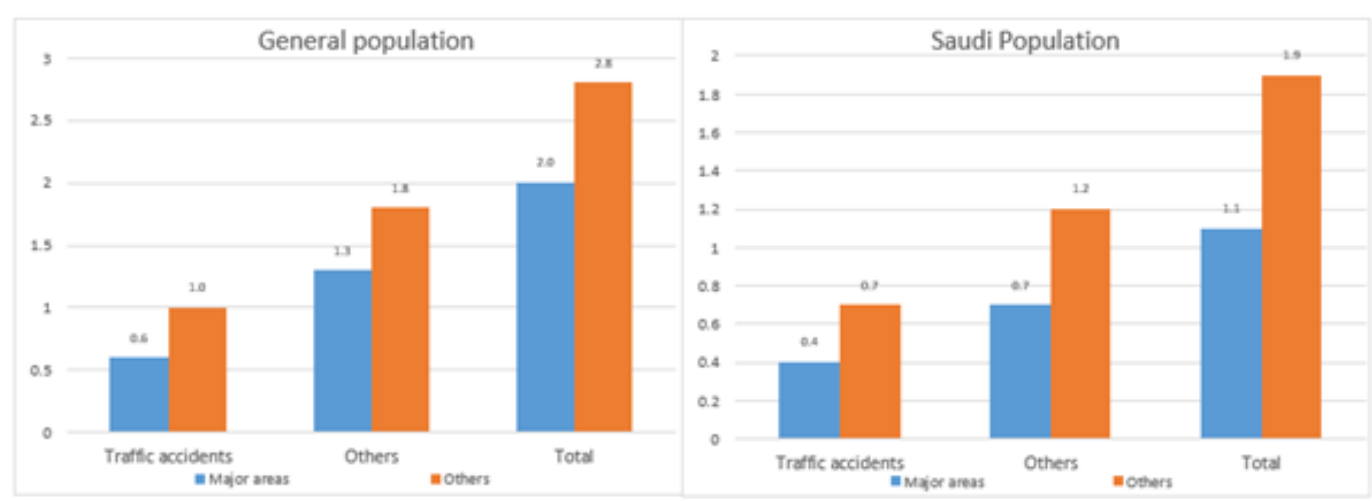

\section{Figure 4}

Sources of injuries by a. broad age groups and b. administrative area classified

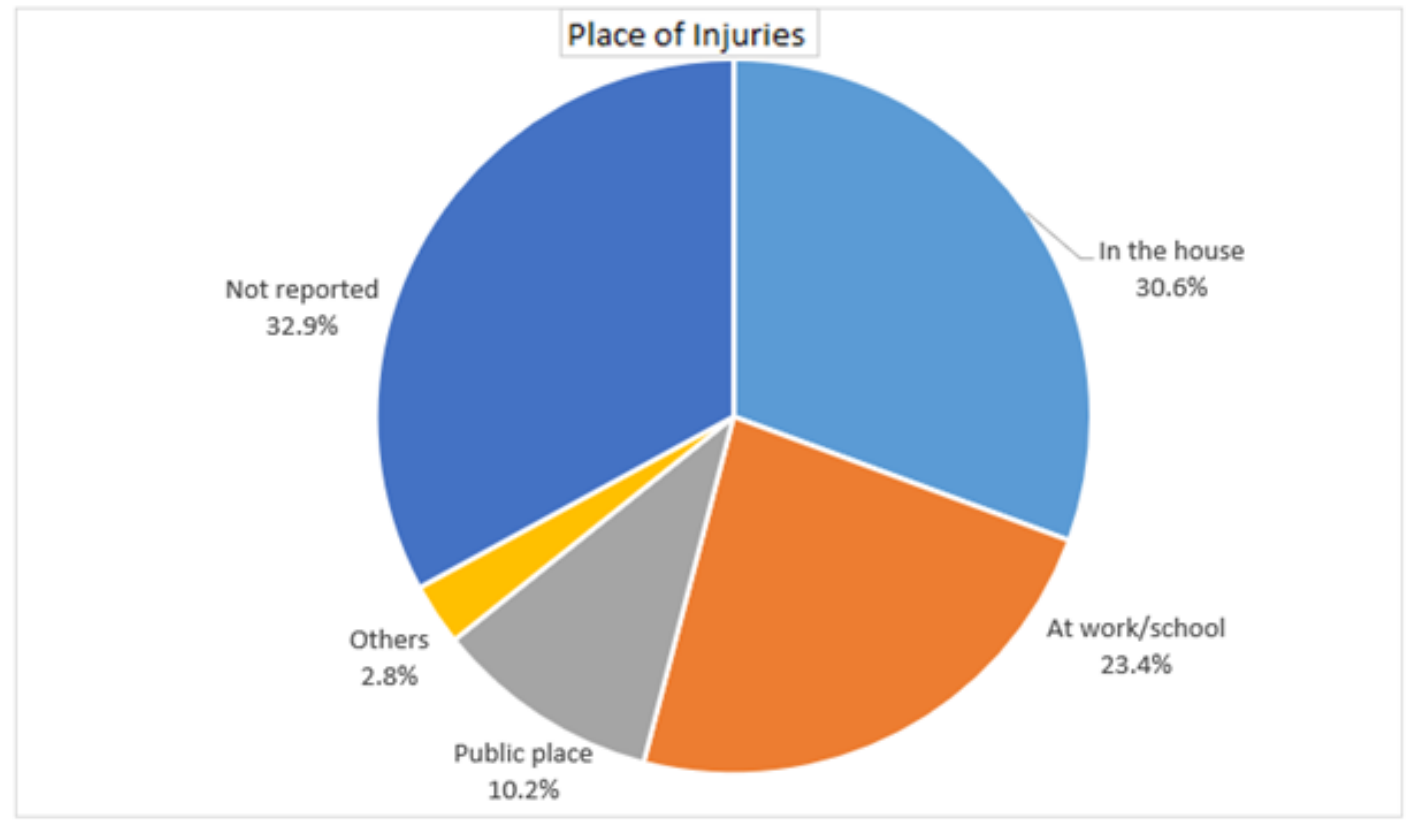

\section{Figure 5}

Distribution of injuries by place 

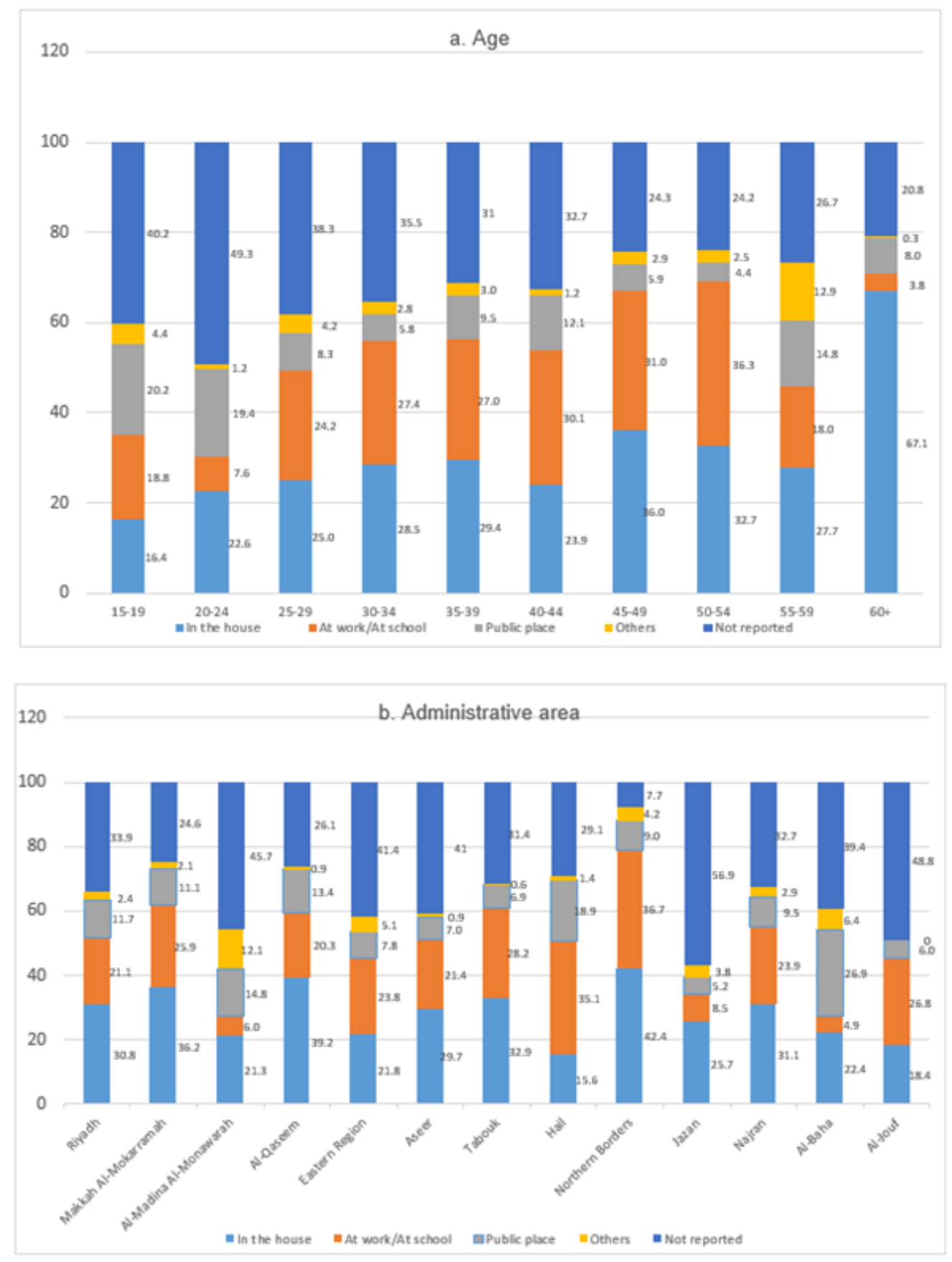

Figure 6

Place of of injury ( 15 years and above) for the general population by a. age and b. administrative area 